\title{
Multimodally Enhanced Opportunities for Language Learning: Gestures Used in Word Search Sequences in ESL Tutoring
}

\author{
Mi-Suk Seo \\ California State University, Sacramento, CA, USA
}

\begin{abstract}
Focusing on word search sequences initiated by ESL learners in conversation tutoring, this study examines how the participants use gestures in order to facilitate language learning as well as mutual understanding. Adopting the methodological framework of Conversation Analysis, it analyzes two particular sequential contexts: (a) when a tutee uses gestures without a candidate solution to her/his word search, directly soliciting the tutor's co-participation; and (b) when a tutee uses gestures with a candidate solution to her/his word search but there is mismatch between the candidate solution and the accompanying gesture. A finegrained analysis of the participants' moment-by-moment verbal and nonverbal actions reveals that gestures create multimodally enhanced opportunities for language learning by allowing the tutor to offer lexical items that are new or unfamiliar to the tutee and/or to provide corrective feedback on the lexical errors. The findings from this study offer implications for the role of gesture in L2 learning and for some of the key concepts in second language acquisition such as output, corrective feedback, and communication strategies.
\end{abstract}

Index Terms - gesture, word search, conversation analysis, second language learning, ESL tutoring

\section{INTRODUCTION}

Although the importance of gesture has been noted in various fields of research for a long time (e.g., Efron, 1941/1972; Ekman, 1976, 1977; Kendon, 1972; Schegloff, 1984), it is a relatively recent development that L2 researchers started to pay serious attention to the role of gesture in second language acquisition (Gullberg, 1998, 2006b, 2010; McCafferty \& Stam, 2008; Stam, 2014). Over the past twenty years, a growing number of studies have provided evidence that gesture plays an important role in second language learning and teaching. For instance, studies conducted in laboratory and instructional settings have shown that gestures facilitate L2 comprehension, helping learners understand verbal input that may be beyond their current level (Allen, 2000; Beliah, 2013; Kellerman, 1992; Lazaraton, 2004; Smotrova \& Lantolf, 2013; Sueyoshi \& Hardison, 2005; Taleghani-Nikazm, 2008). According to the findings from these studies, gestures serve a variety of functions in the context of second language learning and teaching. To be more specific, gestures are used to make input more comprehensible to learners (Allen, 2000; Beliah, 2013; Lazaraton, 2004; Sueyoshi \& Hardison, 2005; Taleghani-Nikazm, 2008), to facilitate encoding and recall of new words (Morett, 2014), to assist cognitive processes in private speech (Lee, 2008; McCafferty, 1998), to create zones of proximal development (McCafferty, 2002), and to mediate the teacher-student negotiation of the meaning of L2 lexical concepts (Smotrova \& Lantolf, 2013). Gestures are also used to track references (Gullberg, 2006a), to establish cohesion across turns-at-talk (Beliah, 2013), to address L2 learners' linguistically problematic utterances (Guvendir, 2011; Seo \& Koshik, 2010; Wang \& Loewen, 2014), to complete turns-at-talk in progress (Mori \& Hayashi, 2006; Olsher, 2004), and to elicit interlocutors' co-participation in word search sequences (Park, 2007; Willey, 2001).

Despite the insightful findings from these studies, there is still not much information available as to how L2 learners use gesture as a multimodal resource in real-time interaction in order to enhance opportunities for language learning as well as to resolve communication problems. Many of the previous studies have examined L2 teachers' gestures or have been conducted in laboratory settings. Moreover, studies that considered L2 learners' gestures have often discussed them as part of communication strategies without providing an analysis of actual instances. Only a handful of studies have provided an in-depth analysis of how L2 learners use gesture in real-time interaction (e.g., Burch, 2014; Mori \& Hasegawa, 2009; Mori \& Hayashi, 2006; Smotrova et al, 2013). In particular, some of the studies (e.g., Eskildsen \& Wagner, 2015; Mori \& Hasegawa, 2009; Park, 2007; Willey, 2001) have suggested that there is a strong link between vocabulary learning and gesture and that word searches are promising sequential contexts where L2 learners are often observed to deploy gesture as a critical resource to facilitate mutual understanding and language learning. Word searches refer to an interactional phenomenon in which a speaker in interaction encounters trouble producing a next item in his/her talk and performs a search typically along with search markers, such as cut-offs, sound stretches, "uh"s, pauses, and the like (Schegloff et al, 1977). The significance of word searches in language learning has been noted by a number of researchers (e.g., Brouwer, 2003; Lee, 2004; Koshik \& Seo, 2012; Willey, 2001). Building on the findings from previous studies, this study aims to enhance our understanding of the sequential organization of word searches by adding a detailed description of the use of gesture. 
Another area that has been underresearched in regard to the role of gesture in L2 interaction and learning is mismatch between L2 learners' gesture and speech. Given L2 learners' limited linguistic resources, it is easily conceivable that they might produce incorrect words while describing nonverbally what they are referring to, but to my knowledge, there have been no studies that investigated L2 learners' gestures that do not match their concurrently produced utterances. Mismatch between speech and gesture has been found to be significant as a predictor of progress in learning. For instance, researchers (e.g., Alibali et al, 1994; Church \& Goldin-Meadow, 1986; Goldin-Meadow et al, 1992; GoldinMeadow \& Alibali, 2013) have observed that children may produce speech-gesture mismatches when they are at transitional states of knowledge and that adult listeners often interpret information that is conveyed only in gestures by these children. In a similar vein, a number of studies (e.g., Cassell et al, 1999; McNeill et al, 1994) have shown that listeners usually attend to the gestures that accompany speech and that speech-gesture mismatches often have consequences for listeners' comprehension, thereby refuting the claim that gesture is not integral to communication and is epiphenomenal to the production of speech. Considering these findings, instances of mismatches between L2 learners' speech and gesture deserve urgent scholarly attention not only to enrich our understanding of the role of gesture in communication in general but also to have further insights into the role of gesture in the interactional process of second language learning.

In an effort to address the research gap mentioned above, this study examines gestures produced in word search sequences during ESL conversation tutoring sessions. In particular, by adopting the methodological framework of Conversation Analysis (CA), the present study analyzes two particular sequential contexts: (a) when a tutee uses gesture without a candidate solution to her/his word search, directly soliciting the tutor's co-participation; and (b) when a tutee uses gesture with a candidate solution to her/his word search but there is mismatch between the candidate solution and the accompanying gesture. This study addresses the following two questions: (a) How does a tutee's gesture used in word search sequences facilitate language learning as well as mutual understanding?; and (b) How does mismatch between the tutee's gesture and speech create extra opportunities for the tutee to learn lexical items that might be slightly higher than their current level? The study also highlights how the participants reach gestural alignments copying each other's gesture - in their collaborative efforts to resolve the contingent problem and discusses how these gestural alignments may promote retaining the target lexical items. The findings from this study offer implications for the role of gesture in L2 learning and for some of the key concepts in second language acquisition such as output, corrective feedback, and communication strategies.

\section{DATA AND METHOD}

The excerpts analyzed in this study are taken from a larger data set that consists of 23 hours of video-recorded oneon-one ESL tutoring sessions. A total of 8 English native-speaker tutors and 8 Korean ESL learners with various proficiency levels participated in the tutoring sessions. The tutors were trained to teach ESL; all of them either had completed an MA TESOL program or were currently enrolled in an MA TESOL program, and they had varying amounts of experience teaching ESL. The sessions from which the excerpts are taken consisted mainly of free conversation between the tutor and tutee, interspersed with moments of pedagogically oriented talk.

The data were collected, transcribed, and analyzed according to the common methodological tenets of Conversation Analysis (Markee, 2000, 2004; Sidnell, 2010). First, some portions of the data were viewed and transcribed without any pre-determined analytic categories. Once gesture was noted as a particularly important element in certain contexts, further investigations were conducted to identify some of the notable sequential contexts where the participants seemed to pay special attention to the gesture. Then, the target excerpts were re-transcribed in more detail and analyzed in a more fine-tuned manner considering the relationship between speech and gesture in the given context. After a recurrent pattern was identified in a few excerpts, an effort was made to find more instances of the pattern in the remaining portions of the data. Finally, the descriptions and analyses of the identified excerpts were compared with transcripts and findings from previous studies to see what similar or unique information the current analysis reveals in regard to the role of gesture in L2 interaction and learning.

\section{DATA ANALYSIS}

\section{A. Gesture Used in Direct Solicitation of Assistance without Candidate Solution}

When L2 learners encounter trouble producing utterances due to their limited linguistic resources, they are often observed to elicit assistance from their interlocutors by saying "I don't know how to say it," or by asking, "How do I say?" (Brouwer, 2003). However, not much has been known as to what makes this solicitation successful and what specific practices are involved. A close examination of the data in my study reveals that gesture plays an important role in leading L2 learners' solicitation to be successful.

Excerpt (1) below shows how the tutee (SK) is first exposed to the target item, which will become a trouble source in excerpt (2). Immediately before the talk in this excerpt, SK asked the tutor (TA) if she brings lunch to school, and TA said she usually brings a sandwich. In line 1, SK pursues more information on this by asking TA what kinds of sandwiches she makes.

(1) [tortilla-1 / TA \& SK / 113005] 
01 SK: uh what kin' of sandwich do you make.

02 TA: w:ell today, I ha:d ham, en: mu- muenster cheese,

03 SK: $\mathrm{u}[\mathrm{h}$

04 TA: [jus' like a type of cheese.

05

06

07

08 SK:

$\rightarrow$ en I [had it in a tortilla,

[((TA puts her hands together with palms up, making a circular shape))

09 TA: en then [I rolled it up,

10

$11 \mathrm{~S}$

12 TA:

13 TA:

14 SK:

15

16 TA

$[((T A$ moves her fingers as if rolling up something $))$

[.hhhh

In line 5, TA first mentions the word "tortilla" with an accompanying iconic gesture. When TA seems to have finished describing the process of making her sandwich in line 10, SK in line 11 responds to TA's talk and indicates that the word "tortilla" is new vocabulary for her with a "change of state token" ("ah:.:.:.") and with a following question ("it's called tortilla?"). In line 15, she uses the new word in her own sentence, but she still seems to be unfamiliar with the word as shown in her cut-off and rising intonation.

About 23 minutes after excerpt (1), SK has been talking about differences between Korea and America in terms of cooking and baking. Starting in line 1 in the excerpt below, SK says that she found ready-to-bake cookies in some American grocery stores.

(2) [tortilla-2 / TA \& SK / 113005]

01 SK: maybe .HHH t! but here: when I: (0.2) uh::: $(0.2) \mathrm{g}$ - went to the:

02 Meijer, or Walmart or like that h they:: sell (dough/the) $(0.2)$

03 like the (0.5) almost fully cooked

04 TA: $\mathrm{mm} \mathrm{hm},=$

05 SK: =cookies. $=$

06 TA: $=\mathrm{mm} \mathrm{hm},=$

07 SK: $=$ it looked $>$ very convenient $[$ but $<$

08 TA:

09 SK:

10 TA:

$=\mathrm{I}$ (didn't) (.) yet: until now I:

$\mathrm{mm}$ hm $[\mathrm{mm}$

$[\mathrm{mm} \mathrm{hm}=$

11 SK: [never use it, but [maybe next time.

12 TA:

[(sure.)

13 SK: -> .Hh but I think next wee:k, I should buy the:: (0.5) you said your

$14 \rightarrow \rightarrow$ sandwich the $[(0.5)$ what?

$15 \rightarrow \rightarrow \quad[((S K$ araws a circle with fingers on the table with

$16 \quad->$

$17 \quad->$

18 TA: $->$ the tortilla. $=$

19 SK: =yeah. tortilla? y[eah.

20 TA:

21 SK:

22 TA:

23 SK:

yeah.

they're [very good. gaze on her fingers and moves her gaze back to TA when she says “what?”))

In lines 7, 9, and 11, SK tells TA that she wants to try ready-to-bake cookies "next time." She then talks about her plan contrastively presented in a more immediate time frame ("but I think next wee:k,"). However, as indicated by a sound stretch ("the::") and a half-second pause in line 13, she displays a problem producing the target item. In her efforts to deal with the trouble, SK provides some clue that is retrievable from their recent interaction ("you said your sandwich"), but may not be very informative in terms of the semantic content of the searched-for-item. In lines 15-17, SK provides a nonverbal description of the searched-for-item: She draws a circle with her fingers on the table. Then, she utters a direct interrogative word ("what?"), shifting her gaze from her hands to TA and thereby eliciting TA's assistance. In the following turn, TA quickly provides the searched-for-item with certainty, as can be noted by her downward intonation. 
Given that language learning is not a cognitive stamping activity that can be achieved in a once-and-for-all manner, L2 speakers may repeatedly have trouble producing and understanding the same yet-to-be familiar linguistic item until they can competently mobilize it in appropriate contexts. As such, although SK was exposed to the new word through interaction less than half an hour ago, she is not yet able to produce it competently. Thus, she resorts to nonverbal resources to achieve mutual understanding as well as to elicit the yet-to-be-familiar item from TA. Note that originally the first mention of "tortilla" is made along with an accompanying gesture by TA (lines 6-7 in excerpt 1), and SK also searches for the word with an iconic gesture. It seems clear that SK's gesture contributes to making her word search a collaborative and successful activity, which can be beneficial in her acquisitional process of the target item.

The following excerpt also provides an example in which a tutee uses gestures during her word search in order to elicit the sought-for-item from her tutor. In this session, the tutor, TE, and the tutee, SG, found out that they both like taking pictures. Prior to this excerpt, SG started to talk about her experience as a photographer at her friend's wedding and said that it is hard to take pictures during ceremonies such as weddings.

(3) [minister / TE \& SG / 102605]

01 SG: en then think about organize the time en film en other stuff.

02 en then I'm:: (0.2) I should no::t u::::m bother $(0.2)$

03 the event itself.=I mean ceremony, so::: but I have to

04 take pictures in some way hh heh heh .hh

05 [during some::: (0.2) speech

$06 \quad[((S G$ moves eye gaze away from $T E))$

07

[((SG raises her $i e_{\text {t }}$ hand and sweeps it down with palm toward TE and eye gaze on TE)) [( $(S G$ produces the same gesture with her right hand as she did with her left hand)) en then [someone::: speech- make [speoch [( $(S G$ maves her right hand higher and between the spaces she used for "bride" and "groom" with eye gaze on TE and holds it))

minister,

usually it's the minister who speaks.

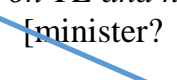
or::: sometimes in the chu:rch catholic church priest? priest.

(0.2) / ((SG makes vertical head shakes several times $))$

so I shouldn:: (0.2) no:t bother

mmheh hhh

26 SG:

them (0.2) to: their do their wo:rk.
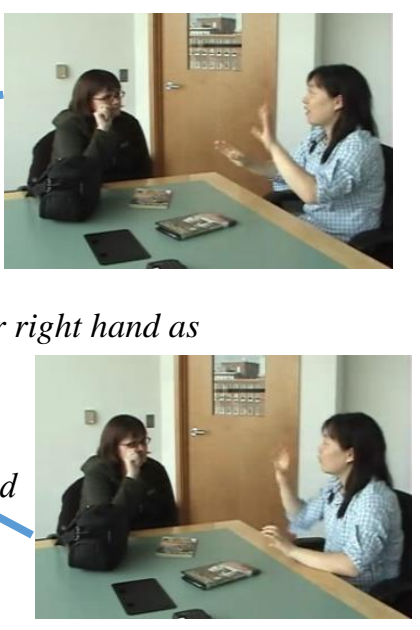

In lines 1 and 2, SG talks about things that she needs to take care of as a wedding photographer. She then tries to explain that, while taking pictures, she should not interrupt the ceremony, but she displays a problem completing her turn at talk (line 5). SG's gaze shift away from TE in line 6 seems to project her word search, shown in the sound stretch "some:::" and the two-tenth second pause (line 5). After producing the delayed item "speech" and moving her gaze back to TE, SG encounters another problem producing the next-due item. But this time she directly requests help from TE by asking "how can you say::" without engaging in further attempts to solve the problem herself. Her direct request without further efforts seems to indicate that her searched-for item is not something that she can retrieve through further efforts, but rather it is something that she has not acquired yet as a language learner. In line 9 , she starts to provide clues for the sought-for-item. She lists the main participants in a wedding, projecting the sought-for item as one of the main categorical members in a wedding ceremony, as indicated in the connective ("en then") following "the bride and groom." She then adds another clue by describing the target member's conventional activity in a wedding ceremony, which results in overlap with TE's candidate solution "minister?".

Now, considering the sequential development of SG's word search, let us look more closely at how SG tries to elicit the searched-for item from TE. SG first asks an explicit question "how can you say::", which TE may not be able to answer without further information from SG, and thus she secures TE's attention for her upcoming talk and concurrent nonverbal conduct. She then provides verbal clues (line 14), but at the same time produces gestures in the space where mutual attention is directed. In particular, she nonverbally describes the configuration of the verbally listed participants in a wedding ceremony. First, she sweeps her raised left hand down in the air while uttering "the bride". Second, for the subsequent word "groom" she does the same gesture with her right hand, but in the right side of the space used for the bride. Finally, with the word "someone:::", which is presented as a substitute for the searched-for item, she raises her 
right hand and holds it in a higher place between the spaces she used for the bride and groom. Thus, her subsequent gestures are produced in coordination with the prior gesture(s), creating interrelationships among themselves. Also, it needs to be pointed out that her gestures convey information that is not included in her verbal utterances. That is, although she refers to someone who makes a speech in a wedding, she is not talking about any random speaker; she is talking about a specific speaker who stands between the bride and groom. Although the detailed information conveyed in SG's gestures is not apparently incorporated in TE's response and TE focuses on the verbally delivered information ("usually it's the minister who speaks."), it is worthwhile to note how L2 speakers actively mobilize nonverbal resources to facilitate their L1 interlocutors' participation in their word searches.

From a slightly different perspective, the examples in this section seem to show some features that are different from previous studies on gestures in word searches. First, some researchers have claimed that the primary function of gesture is not to communicate to the recipient but to support the speakers' encoding of information (Freedman, 1972; Rime, 1982 cited in Cassell et al, 1999). However, it may be different in the case of L2 speakers who do not have adequate linguistic resources to encode and try to resort to their interlocutors' linguistic expertise for expanding their linguistic repertoire as well as for accurate communication. The tutees in the above examples were observed to produce gestures to elicit the target word from their tutors as well as to communicate the semantic information of the searched-for item. Gestures are not produced while the tutees are trying to retrieve the searched-for items through their cognitive processing. They are specifically used for communicative purposes and thus they are more interactionally-oriented rather than cognitively-oriented. Second, studies on word searches in L1 interaction (e.g., Hayashi, 2003) have shown that gestures in word searches are used as resources that enable interlocutors to participate in co-constructing the current speaker's action-in-progress. This holds true for the instances presented in this section. However, there also seem to be some sequential differences between the cases in L1 interaction and those in this section. Although it might not always be true, the tutees in the above examples seem to use some discursive practices to secure their tutors' attention before they produce gestures and make their tutors' co-participation conditionally relevant by launching a side sequence. For example, in excerpt (2), SK says "you said your sandwich the" before she nonverbally describes the item that is due after the article "the". By invoking some contextual information that involves the recipient (i.e., "you"), the tutee seems to try to secure her tutor's attention for her upcoming nonverbal description. Also, as mentioned above, the tutee in excerpt (3) achieves the same effect by directly asking "how can you say::" before she provides verbal and nonverbal clues.

\section{B. Mismatch between Gesture and Concurrently Produced Candidate Solution}

Streeck (2003) examined how speech-gesture mismatch engenders self-repair in L1 German interaction. He stated that the mismatch between bodily enactment and concurrent talk may occur due to the fact that the speaker sometimes does not see what his/her body is doing. According to Streeck, in these cases the speaker's mind and body are divided and the mismatch often results in the speaker's self-repair of the prior problematic utterance. While Streeck discussed how speakers repair their prior utterances when they realize there are mismatches between gesture and talk, Seyfeddinipur (2007) presented some instances in which speakers repair their prior gestures while repeating their prior utterances, orienting to their prior gestures as inaccurately representing the concurrent talk. Except for these two studies, to my knowledge, repair that occurs due to mismatches between gesture and talk has rarely been discussed in studies on L1 interaction, much less in those on L2 interaction.

Considering what Streeck (2003) and Seyfeddinipur (2007) found in their studies, the examples that I found in my data set seem to illustrate different situations. In particular, the following differences are noted. First, the mismatch between gesture and talk in my data occurs during word search activities. Second, the mismatch does not seem to occur because the speaker's mind and body are divided without the speaker's awareness, but because the speaker's linguistic resources available at the moment do not allow him/her to accurately verbalize the target items or activities, while their bodies know how to represent them. Finally, the speakers often seem to be aware of the potential incongruence between their gesture and utterance because they often solicit the interlocutors' confirmation on the accuracy or suitability of their utterances.

In the following example, the tutor, TL, and the tutee, $\mathrm{SH}$, have been talking about the places SH wants to visit before she goes back to Korea. SH mentioned an Amish village as a candidate and introduced a similar village in Korea, describing their lifestyle compared to that of Amish people.

(4) [moustache / TL \& SH / 101605]

01 TL: $\quad$ is it because (or) (.) this (.) so the Amish people

02 SH: mm::=

03 TL: =are:: (0.2) doing this because of their religion,

04 [what about the (.) people there.

$05 \mathrm{SH}: \quad[\mathrm{mm}$

06 TL: is it also because of a religion? or just:

$07 \mathrm{SH}: \mathrm{hm}$

08 TL: tradition.

$09 \mathrm{SH}$ : religion.

10 TL: it i:s $\left(^{\circ}{ }^{\circ}\right)$ 
11 SH: yeah. religion. yeah. uh use to:: $(0.2)$

12

13

14

15

16

17

18

19

$20 \mathrm{SH}$

21

22

23 TL:

$\rightarrow$ [uh st- mousta:che?

-> [((SH taps her chin ana Jurrows

her eyebrows, gazing at $T L)$ )

TL: $\rightarrow \quad$ [beard?

$\rightarrow \quad[(($ TL sweeps her chin with right hand $))$

SH: -> bea(h)rd. yea[h.

TL: $\quad$ [mustache is here.=

[(TL taps above her upper

=yeah. [ah:: y[eah. mustache en beard.

[((SH puts left hand above her upper lip and moves her fingers around her mouth in the shape of goatee))

[mustache ${ }^{\circ}$ beard $^{\circ}$

[((TL taps above her upper lip and chin $))$

25 SH: no cutting

26 TL: $\mathrm{mm}$

In lines 1 through 10, TL asks SH whether the people in the Korean village keep their specific lifestyle because of their religion or tradition, and SH answers that it is because of their religion. In line 11, going back to her prior description of their lifestyle, SH starts a new sentence without a subject ("use to::"), but she encounters a problem continuing her talk as signaled by a number of non-lexical speech perturbations, such as a sound stretch ("to::"), a twotenths-of-a second pause, a filler ("uh"), and a cut-off ("s-"). These are common characteristics of word searches as described by Schegloff et al. (1977) and Goodwin and Goodwin (1986). Finally, in line 12, she produces a candidate solution, "musta:che?" with accompanying gesture (i.e., tapping her chin and furrowing her eyebrows with eye gaze on TL), but asks for TL's confirmation with rising intonation. Responding to SH's confirmation request, TL, in line 15, disconfirms SH's candidate solution by proffering an alternative item that matches with SH's gesture, while copying SH's gesture. Subsequently, SH accepts it in line 17 by repeating the alternative and producing an acknowledgement token, "yeah."

As shown in Hosoda's (2006) and Willey's (2001) studies, this way of sequential development in word search constitutes distinctive features of L2 interaction, engendered by L2 speakers' orientation to their L1 interlocutors' linguistic expertise as relevant in resolving their trouble. However, the above example pinpoints one specific aspect that needs closer attention in understanding the critical role of gesture in L2 speakers' word search sequences. That is, without SH's gesture, TL would not have proffered the alternative item "beard," because no other verbal contextual clues have been provided by SH to imply that the people in the Korean village grow beards rather than moustaches. A full understanding of the sequential development (i.e., "why that now" regarding the tutor's correction) becomes available only when the participants' nonverbal behaviors are considered.

Now, let us take a closer look at the way TL responds to the mismatch between SH's utterance and gesture. Technically, TL could respond in a different way. That is, she could repair SH's gesture by tapping above her upper lip, while repeating SH's original utterance, "moustache." However, TL chooses to repair SH's utterance instead of her gesture, displaying her understanding that SH's limited linguistic competence might have caused the mismatch. This is somewhat similar to how adult listeners often interpret information that is conveyed only in gestures when they encounter mismatches between children's speech and gesture (Goldin-Meadow et al, 1992). On the other hand, it is also different from adult responses to similar instances with children in that TL leaves room for SH, the original speaker, to revise TL's understanding, in case SH finds it problematic. First, she copies SH's gesture as shown in line 15, making it possible for SH to see her own original gesture and showing on what grounds she provides the item "beard." Second, she uses rising intonation ("beard?"), signaling her uncertainty regarding which was problematic (i.e., SH's utterance or gesture) and thus eliciting SH's confirmation. Overall, SH's gesture in line 13 enabled TL to detect SH's inaccurate language use and to have an incidental opportunity to add a pedagogical explanation of potentially confusing vocabulary items (line 18), also using similar gestures.

The next excerpt provides a similar instance in demonstrating the role of gesture in engendering the interlocutor's repair that may be acquisitionally beneficial for the L2 learner's language development. In this excerpt, the tutee (SK) has been telling a story to the tutor (TA) about her experience related to pizza. Some decades ago, when pizza was first introduced in Korea, SK's elder sister tasted it in a restaurant and recommended it to her family, so SK's mother bought one frozen pizza, which was rare in those days.

(5) [put out / TA \& SK / 110705]

01 SK: she: bought some frozen pi[zza.

02 TA:

[YEA::h [yeah.

03 SK:

04

05 TA:

that times it was not: (.) usual too

[yeah. that- (.)

06 SK: [yea:h yeah. yea:h yeah. so: I::: $(0.5)$ e- en:: 
07

08 TA:

09 SK:

10

11 TA:

12 SK:

13

14 TA:

15 SK:

16 TA:

17

18

19

20

21

22

23

24

25 TA

26 SK:

27 TA:

28 SK:

29 TA:

30 SK:

31 TA:

32 SK:

33

34

she:::: put it the: refrigerator,

$\mathrm{mm}$ hm,

en with my second sister, [no:t her.

[((SK raises left hand and points to left $))$

right. $=$

=yeah. with my second sister, she didn' know about pizzas

very well.

uh huh,

me too.

uh huh,

so we:::

(0.5) [uh:: we:: (.) put: out? (it: uh-)=

$\rightarrow$

$->$

[((SK raises hands and moves them away

from her torso and then moves them back

$\rightarrow>$ toward her torso, gazing at TA))

TA: $->=[$ took it ou[t?

[((TA moves hor right hand toward her torso $))$

$\mathrm{K}:->$

[ah yah. we toon it aut. .H heh heh heh

we $\operatorname{did}(\mathrm{h}) n$ ' [.h heh put $\mathrm{i}(\mathrm{h}) \mathrm{n}$ a microwa(h)ve.

[heh heh heh heh HEH HEH HEH HEH HEF

[we thought [it was do- it was do::ne.

[h h h [you (hh) ate i(h)t. heh heh heh

[it was do(hh)ne. .HHHH perfectly done:: foo- uh: =

[h h h

=done foods. $=$

$=$ YEA:[h. like $\mathrm{p}$ - heh pre- heh heh heh

[finish so we: hehhh $\mathrm{i}(\mathrm{h}) \mathrm{t}$ was very:: uheh difficult

to: separate the piece en piece piece by piece so:: we:::

broke it with hammer,

In lines 1 through 7, SK tells TA that her mom bought a frozen pizza and put it in the refrigerator. In lines 9 through 15 , she seems to build up some background information to contextualize the upcoming main part of the story. To summarize what SK says, both she and her second sister were not familiar with pizza. Thus, starting with an upshot marker, "so," in line 17, SK launches a new sentence, but immediately she displays trouble producing a next item due after the subject "we," as shown in a sound stretch ("we:::::"), a half-second pause, and a filler ("uh::"). She then restarts her sentence, but still cannot produce the searched-for item as it is delayed by another sound stretch and a micro pause. Finally, she produces a candidate solution ("put: out?") with accompanying gesture (i.e., moving her raised hands toward her torso as if taking something out of some storage place) and rising intonation, soliciting TA's confirmation on the accuracy of the produced item. In line 21, TA provides an alternative expression in a way that is similar to TL's response in excerpt (4) (i.e., with rising intonation). Subsequently, in line 23, SK accepts TA's alternative candidate and reproduces her prior sentence in an accurate form (i.e., from "we put out it" to "we took it out"), incorporating TA's correction.

The sequential development of the word search activity in this excerpt deserves a more thorough analysis. From TA's perspective, it might not be easy to understand what word(s) SK is searching for or what kind of activity SK is trying to describe, given that SK has not provided enough contextual clues, such as "we wanted to eat it," or "we opened the refrigerator." The way SK proceeds with her story does not project a pragmatically transparent trajectory, because she basically says, "both my second sister and I did not know about pizza, so we...." Then, how is TA able to provide successfully an accurate phrase that SK has been searching for, potentially correcting SK's candidate solution? It seems that the mismatch between SK's utterance and gesture (in lines 17-20) contributes to engendering TA's prompt correction. It is obvious that SK's gesture does not match her candidate solution "put out": The accurate gesture for "put out" would be moving her raised hands away from her body, instead of moving her hands toward her body as she does. Without the accompanying gesture, the phrase "put out" might not be easily detected as problematic and repaired by TA TA, as a recipient, does attend to the accompanying gesture and incorporates the information conveyed in the gesture in her response to SK's utterance, producing a similar gesture. Also, it should be noted that TA orients to SK's utterance as repairable, not her gesture, in the same way as TL did in excerpt (4), possibly assuming that SK does not have adequate linguistic resources available at the moment to describe something that her body can enact more accurately. Finally, as a recipient of the story, TA leaves room for SK to confirm the proffered alternative item, since SK has the epistemic authority in the described activity.

In terms of language learning, it seems clear that the speech-gesture mismatch contributes to occasioning an opportunity for SK to get corrective feedback that can be acquisitionally beneficial. Also, as shown in SK's repetition of TA's correction (line 23), SK gets a chance to practice the target phrase that is lexically revised as well as syntactically 
modified from her prior problematic form (i.e., the correct position of the pronoun "it" as an object of a phrasal verb: "put out it" -> "took it out").

The next example, extracted from the same pair's tutoring session three weeks after the session that generated excerpt (5), provides a similar, but more complex situation regarding how speech-gesture mismatch becomes consequential for the unfolding interaction. In this session, SK has been telling TA about her recent trip to a neighboring city. Prior to the talk in this excerpt, SK said that she really enjoyed the dinner at a Japanese buffet restaurant in the city and TA asked some questions about the restaurant.

(6) [crab / TA \& SK / 112805]

01 TA: what was your favorite.

02 SK: u::::::m::::: shrimp, (0.2) the cooked shrimp, (0.2)

03

with some sau:ce, en::: $(0.5)$ uh:......

[(0.5) uh:=

[((SK raises her hands to her sides and moves her fingers in a way

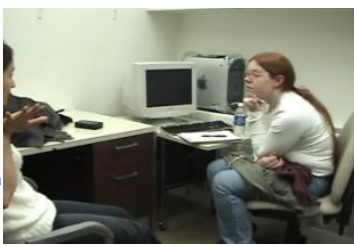

that is similar to movement of crab's legs, and holds the gesture.))

08 SK:

09 TA:

$=\mathrm{HEH} \mathrm{HEH}[\mathrm{HEH}$ hehh

is it [seafood?

$$
\text { [I cut-/can't- suddenly I forgot the::: .hh }
$$

10 SK:

11 SK:

12 TA:

[word.

yeah. seafood.

lots of legs?

uh:::: (.) lobster.

lobster?

yeah. $=$

$=[$ lobster? $=$

[((TA raises her left hand in front of her torso and moves her

fingers and thumb in a way that is similar to the movement

of a lobster.))

SK: $=$ lobster. [=not lobster.

[( $(\mathrm{S} \Lambda$ moves her hands to the front of her body, making her index fingers sick out together, and then quickly moves

crab. her hands back to the prior position))

ah: [crab. yea:h.

[((SK finally releases her gesture held from line 5 and pusts her ands together in front of her torso in a clapping motion)) there're like eight [leg[s.

\section{[( (TA pus her hands together in front of her torso and moves her Jingors as if mimicking the movement of a crab with guse on her hands))}

okay.

[yea:h yea:h yea:h yea::h.

uhhhhhh

that's my [oh I love crab.

[yeah en: lobster too.

wow.=

=yeah.

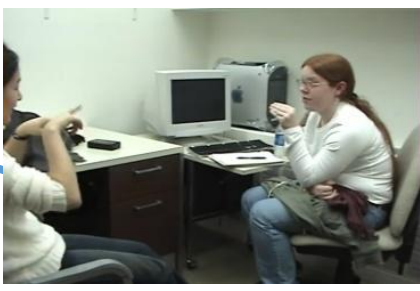

In lines 1 through 3, TA asks SK what her favorite food was and SK starts to list her favorite food items. However, as shown in the sound stretch ("en:::”), a half-second pause, and the filler ("uh:::::::") in line 3, SK displays trouble producing the next item due for her favorite food list. As she still cannot come up with the target item after an initial search, SK in lines 5 and 6 produces an iconic gesture to describe the searched-for item, accompanying another halfsecond pause and the filler ("uh:") in line 4. Subsequently, in overlap with TA's laughter and information seeking question ("is it seafood?"), SK explicitly admits that she forgot the word (lines 8 and 10). Building on SK's positive answer in line 11, TA in line 12 asks another question ("lots of legs?"), demonstrating her efforts to achieve mutual understanding as well as to resolve SK's word search as a co-participant. In the following turn, SK finally comes up with a solution ("lobster.") after another filler and a micro pause. It is interesting to note how SK's solution is phonetically related to TA's utterance in line 12. According to Jefferson's (1996) study on word selection, people often make errors by producing "sound-selected" utterances triggered by certain sounds that are included in the prior talk (whether it is their own or their co-participants' talk). As such, it is possible that SK's solution "lobster" is selected 
among the categorical members of seafood under the influence of the alliteration (i.e., /1/) of TA's words "lots" and "legs."

Possibly noticing the mismatch between SK's gesture and verbal solution, TA repeats the solution with rising intonation, thereby asking for SK's confirmation. In the subsequent turn, SK confirms TA's candidate hearing or understanding. Although her repair initiation has been completed by the original speaker, SK, TA in line 16 repeats the trouble source once more with rising intonation, but this time with an accompanying iconic gesture: She raises her left hand and moves it in a way that is similar to the movement of a lobster. By producing an alternative gesture that is different from SK's gesture, TA implicitly asks, "Are you sure it's lobster? Lobster looks like this." It is noteworthy that TA's response to SK's speech-gesture mismatch is different from TL's response to SH's speech-gesture mismatch in excerpt (4). That is, TA corrects SK's gesture while repeating SK's verbal utterance, whereas TL corrected SH's utterance while copying SH's gesture. The reason might be that, as marked through intonational differences in the delivery of their word search results (i.e., "mousta::che?" vs. "lobster."), SH's solution (line 12 in excerpt 4) was produced as a candidate solution, inviting TL's correction, while SK's solution in line 13 is produced with certainty as a final solution, not as an item that still needs the tutor's confirmation. Alternatively, it might be that SK's gesture is not so communicatively transparent as to enable TA to offer an alternative lexical item rather easily.

In line 20, although SK first confirms TA's verbal repetition accompanied by gesture, she quickly disconfirms it, while copying TA's gesture to some extent (lines 21 through 23). TA's alternative gesture might have led her to realize the incorrectness of the solution "lobster," as her body also reacts in a way that reveals and repairs the mismatch. Following SK's disconfirmation, TA finally provides an alternative item ("crab") with certainty as noted in its falling intonation (line 24). Subsequently, SK accepts it as the searched-for-item by producing a change-of-state token "ah:" and repeating the proffered item, followed by an acknowledgement token "yeah." Note that SK finally releases her original gesture held from line 5 (lines 26 and 27). Now that SK's word search has been successfully resolved, TA and SK may resume the interrupted main sequence. However, TA in line 28 starts to provide more detailed information about the trouble source with an accompanying gesture, possibly in order to make sure that it is indeed the searched-foritem considering SK's previously repeated confirmation of the problematic solution. Faced with TA's attempt to expand the already completed search, SK in line 32 produces a response token "yea:h" and repeats it multiple times, starting even before TA completes her turn. As Stivers (2004) noted of examples in similar sequential environments, SK's multiple sayings of "yea:h" seem to display her orientation to TA's sequential expansion as unnecessary and thus show her determination to stop TA's persistent action, claiming that the proffered information is already well known to her and that the word "crab" is indeed the searched-for-item. Finally, TA seems to be convinced of the successful resolution of SK's word search, as shown in her sequence closing "okay" (line 33). In the following turns (lines 35 and 36), TA and SK resume the main sequence that was interrupted due to SK's word search. In sum, in contrast to excerpts (4) and (5) in which the tutees' utterances were negotiated, excerpt (6) has shown how gesture also can be negotiated, although it is ultimately the utterance that is corrected.

The last excerpt below also shows how a mismatch between the tutee's gesture and the concurrently produced lexical item creates an opportunity for the tutor to provide a more accurate lexical item that the tutee might not have fully acquired yet. In this excerpt, the tutor, TA, and the tutee, SK, have been talking about babysitting and how hard it is to take care of a baby, sharing their related experiences and stories. SK said that a few years ago when her sister had a baby, her mother took care of him for a while and tries to describe how demanding and difficult it was for her mom.

(7) [wrinkles / TA \& SK / 112805]

01 SK: $\quad$ after (.) she::: took: care of him, yeah.

02 show:: (0.5) [every: I saw: (.) every day:

$03 \quad[((S K$ puts her index finger

$04 \quad$ on her chin))

05 her: [lips um::: (1.5)

06

09 TA:

$10 \mathrm{SK}$ :

11 TA:

12 SK:

13

14

15 TA:

16 SK:

17 TA:

18 SK:

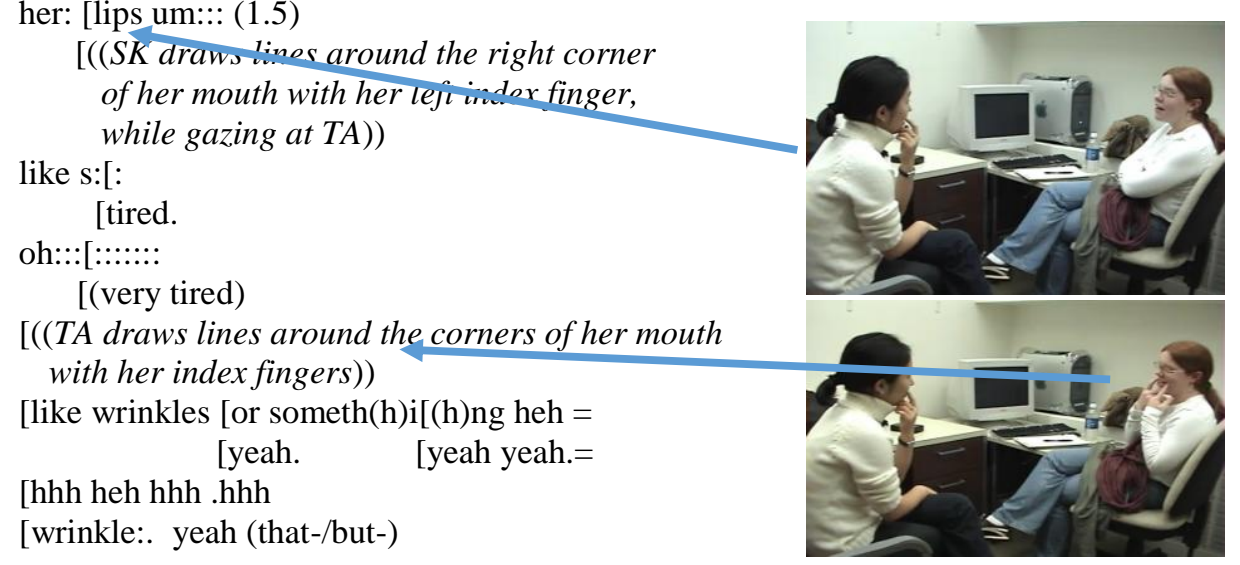


After SK says "I saw everyday her lips" in lines 2 through 5, she encounters trouble continuing her talk and engages in word search, as shown in the filler "um:::" and the one-and-a-half-second pause. Also, starting right before the word search, she uses gesture to describe the searched for item. More specifically, as the figure shows, she repeatedly draws lines around the right corner of her mouth with her left index finger, while gazing at TA. In line 10, SK finally comes up with a solution to her word search, saying "tired" with falling intonation, and repeats it by adding the modifier "very" (line 12). However, it needs to be noted that there is discrepancy between SK's gesture and her final solution to the word search. Facing this discrepancy, TA copies SK's gesture as shown in the second figure and provides an alternative item "wrinkles" in a modulated form (line 15). Subsequently, SK produces an acknowledgement token "yeah" three times and repeats the word provided by SK in line 18. It is obvious that if SK had not produced gesture along with her utterance (i.e., without the observable mismatch between SK's gesture and utterance), TA would not have been able to offer a linguistically more accurate item that SK was not able to produce spontaneously. From an analytic perspective, without access to the video data we may not properly understand why TA provides corrective feedback with the specific alternative word "wrinkles" after the original speaker, SK, successfully produces the solution with indicated certainty.

\section{SUMMARY AND DISCUSSION}

This study examines how gestures are deployed as critical resources in L2 learners' word search sequences and how they facilitate language learning as well as mutual understanding. The excerpts analyzed in this study show that the tutees sometimes produce gestures without a candidate solution, directly asking the tutor to provide a lexical item that matches their gestures, and other times they produce gestures with a mismatched verbal candidate solution, enabling their tutors to provide corrective feedback on their lexical errors. In both cases, the tutees' gestures contribute to mutual understanding by making visually available the intended semantic content of the lexical items that they do not know or that they cannot produce competently. It is noteworthy that the participants often copy each other's gestures and these gestural alignments make the moment-by-moment process of co-constructing intersubjectivity publicly observable. It can also be argued that the tutees' gestures facilitate language learning even though there is no longitudinal evidence available. It creates interactionally motivated opportunities for the tutees to listen to and produce in a meaningful way the lexical items that might be beyond their current level. In their overview of the relationship between gesture and language development, Goldin-Meadow and Alibali (2013) introduced empirical research and relevant theories that showed how children's gestures play a positive role in their vocabulary development. Their review suggested that the more gestures children produce to convey the meaning of unknown lexical items, the better chances there are for them to learn and retain those lexical items. Even though children's first language acquisition and adults' second language acquisition may involve different processes, the findings from studies on gesture and children's language development seem to provide theoretically well-grounded arguments, highlighting a positive role of gesture in second language learning, particularly in vocabulary learning.

This study offers implications for some of the key concepts that are commonly used in the field of second language acquisition. For instance, Swain (1985) claimed that L2 learners' output is crucial for their language development. One of the reasons for this claim is because L2 learners' output allows them to test their hypotheses and enables them to get corrective feedback from their interlocutors. However, the notion of "output" has been discussed based only on L2 learners' verbal output, as the majority of mainstream SLA studies depend on audio data. As the close analysis of the examples in this study has shown, it is clear that L2 learners' gestures are an integral part of their output and play a critical role in engendering L1 speakers' corrective feedback, which researchers argue is beneficial for language development. As such, the term "output" needs to be reconceptualized in a way that incorporates both verbal and nonverbal aspects of what L2 learners produce in interaction.

In a similar vein, this study has demonstrated how important it is to include the nonverbal aspects of interaction in understanding the sequential development of corrective feedback. The majority of studies on L2 teachers' corrective feedback have been dependent on audio data, often providing decontextualized segments. However, as shown in some of the examples in this study, without taking L2 learners' gestures into account, it might not be possible to fully understand why an interlocutor or teacher provides corrective feedback on a lexical item that seems to be semantically suitable in the given context.

Finally, the findings from this study lend support to Burch's (2014) convincing argument that the term "communication strategies" needs to be respecified from an interactional perspective and we need to pay closer attention to how L2 learners deploy locally available resources, verbal and nonverbal, in collaboration with the coparticipants. In most of the traditional literature on communication strategies, L2 learners were viewed as deficient communicators (Firth \& Wagner, 1997) and their use of gesture was considered as an outcome of their individualized remedial effort to deal with their linguistic deficiencies. However, the examples analyzed in this study clearly show how the tutees, as resourceful learning agents, are able to enhance their opportunities for language learning by using multimodal resources and by transforming the linguistic contingency into a social activity that requires co-participants' collaboration. 


\section{APPENDIX. TRANSCRIPTION NOTATION}

$\begin{array}{cl}{[\quad[} & \text { Overlapping utterances } \\ = & \text { Latching: when there is no interval between adjacent utterances } \\ (0.0) & \text { Timed silence within or between utterances in tenths of a second } \\ - & \text { A glottal stop, or abrupt cutting off of sound } \\ (\quad) & \text { Uncertain hearing } \\ ((,)) & \text { Transcriber's remark } \\ : & \text { Elongated sound } \\ . & \text { Falling intonation, e.g., sentence final } \\ , & \text { Continuing intonation, e.g., phrase final } \\ ? & \text { Rising intonation } \\ \text { underline } & \text { Stressed sound } \\ & \quad \text { Quieter than surrounding talk } \\ \uparrow \downarrow & \text { Marked change in pitch: upward or downward } \\ \text { hhh } & \text { Audible outbreath } \\ . \text { hh } & \text { Audible inbreath } \\ (\text { hh) } & \text { Laughter within a word } \\ < & \text { Utterance is delivered at slower speed than surrounding talk } \\ > & \text { Utterance is delivered at quicker speed than surrounding talk }\end{array}$

\section{REFERENCES}

[1] Alibali, M. W., \& Goldin-Meadow, S. (1993). Gesture-speech mismatch and mechanisms of learning: What the hands reveal about a child's state of mind. Cognitive Psychology, 25, 468-523.

[2] Allen, L.Q. (2000). Nonverbal accommodation in foreign language teacher talk. Applied Language Learning, 11, 155-176.

[3] Belhiah, H. (2009). Tutoring as an embodied activity: How speech, gaze, and body orientations are coordinated to conduct ESL tutorial business. Journal of Pragmatics, 41, 829-841.

[4] Belhiah, H. (2013). Using the hand to choreograph instruction: On the functional role of gesture in definition talk. The Modern Language Journal, 97, 417-434.

[5] Brouwer, C. E. (2003). Word searches in NNS-NS interaction: Opportunities for language learning? The Modern Language Journal, 87, 534-545.

[6] Burch, A. (2014). Pursuing information: A conversation analytic perspective on communication strategies. Language Learning, 64, 651-684.

[7] Cassell, J., McNeill, D., \& McCullough, K. (1999). Speech-gesture mismatches: Evidence for one underlying representation of linguistic and nonlinguistic information. Pragmatics and Cognition, 7, 1-33.

[8] Church, R. B., \& Goldin-Meadow, S. (1986). The mismatch between gesture and speech as an index of transitional knowledge. Cognition, 23, 43-71.

[9] Efron, D. (1972). Gesture, race, and culture. The Hague: Mouton. [Reissue of Efron 1941].

[10] Ekman, P. (1976). Movements with precise meanings. Journal of Communication, 26, 14-26.

[11] Ekman, P. (1977). Biological and cultural contributions to body and facial movement. In: Backing, J. (Ed.), The anthropology of the body (pp. 39-84). London: Academic Press.

[12] Eskildsen, S. W., \& Wagner, J. (2015). Embodied L2 construction learning. Language Learning, 65, 268-297.

[13] Firth, A., \& Wagner, J. (1997). On discourse, communication and (some) fundamental concepts in second language acquisition research. Modern Language Journal, 81, 285-300.

[14] Freedman, N. (1972). The analysis of movement behavior during the clinical interview. In A. Siegman \& B. Pope (Eds.), Studies in dyadic communication. New York: Pergamon.

[15] Goldin-Meadow, S., Wein, D., \& Chang, C. (1992). Assessing knowledge through Gesture: Using children's hands to read their minds. Cognition and Instruction, 9(3), 201-219.

[16] Goldin-Meadow, S., \& Alibali, M. W. (2013). Gesture's role in speaking, learning, and creating language. Annual Review of Psychology, 64, 257-283.

[17] Goodwin, C. (1986). Gesture as a resource for the organization of mutual orientation. Semiotica, 62, 29-49

[18] Goodwin, C., \& Goodwin, M. (1986). Gesture and coparticipation in the activity of searching for a word. Semiotica, 62, 51-75.

[19] Gullberg, M. (1998). Gesture as a communication strategy in second language discourse. Lund, Sweden: Lund University Press.

[20] Gullberg, M. (2006a). Handling discourse: Gestures, reference tracking, and communication strategies in early L2. Language Learning, 56, 155-196

[21] Gullberg, M. (2006b). Some reasons for studying gesture and second language acquisition. International Review of Applied Linguistics, 44, 103-124.

[22] Gullberg, M. (2010). Methodological reflections on gesture analysis in second language acquisition and bilingualism research. Second Language Research, 26, 75-102.

[23] Guvendir, E. (2011). The role of non-verbal behavior of teachers in providing students corrective feedback and their consequences. Sino-US English Teaching, 8, 577-591.

[24] Hayashi, M. (2003). Language and the body as resources for collaborative action: A study of word searches in Japanese conversation. Research on Language and Social Interaction, 36, 109-141.

[25] Hosoda, Y. (2006). Repair and relevance of differential language expertise in second language conversations. Applied 
Linguistics, 27, 25-50.

[26] Kendon, A. (1972). Some relationships between body motion and speech. In A. W. Seigman \& B. Pope (Eds.), Studies in dyadic communication (pp. 177-210). Elmsford, NY: Pergamon.

[27] Kendon, A. (2004). Gesture: Visible action as utterance. Cambridge: Cambridge University Press.

[28] Koshik, I., \& Seo, M. (2012). Word (and other) sequences initiated by language learners. Text \& Talk, 32(2), 167-189.

[29] Lazaraton, A. (2004). Gesture and speech in the vocabulary explanations of one ESL teacher: A microanalytic inquiry. Language Learning, 54, 79-117.

[30] Lee, D. S. (2004). Conversation analytic approach to communication strategies: Appeals in language learners' word searches. Unpublished Master's thesis. University of Illinois, Urbana-Champaign.

[31] Lee, J. (2008). Gesture and private speech in second language acquisition. Studies in Second Language Acquisition, 30, 169190.

[32] Markee, N. (2000). Conversation analysis. Mahwah, NJ: Lawrence Erlbaum.

[33] Markee, N. (2004). Conversation Analysis for second language acquisition. In E. Hinkel (Ed.), Handbook of research in second language teaching and learning (pp. 355-374). Mahwah, NJ: Lawrence Erlbaum.

[34] McCafferty, S. G. (1998). Nonverbal expression and L2 private speech. Applied Linguistics, 19, 73-96.

[35] McCafferty, S. G. (2002). Gesture and creating zones of proximal development for second language learning. The Modern Language Journal, 86, 192-203.

[36] McCafferty, S. G., \& Ahmed, M. (2000). The appropriation of gestures of the abstract by L2 learners. In J. P. Lantolf (Ed.), Sociocultural theory and second language learning (pp. 198-218). Oxford: Oxford University Press.

[37] McCafferty, S. G., \& Stam, G. (Eds.). (2008). Gesture: Second language acquisition and classroom research. New York: Routledge

[38] McNeill, D. (1992). Hand and mind: What the hands reveal about thought. Chicago: University of Chicago Press.

[39] McNeill, D., Cassell, J., \& McCullough, K. (1994). Communicative effects of speech mismatched gestures. Research on Language and Social Interaction, 27, 223-237.

[40] Morett, L. M. (2014). When hands speak louder than words: The role of gesture in the communication, encoding, recall of words in a novel second language. The Modern Language Journal, 98, 834-853.

[41] Mori, J., \& Hasegawa, A. (2009). Doing being a foreign language learner in a classroom: Embodiment of cognitive states as social events. International Review of Applied Linguistics, 47, 65-94.

[42] Mori, J. \& Hayashi, M. (2006). The achievement of intersubjectivity through embodied completions: A study of interactions between first and second language speakers. Applied Linguistics, 27, 195-219.

[43] Olsher, D. (2004). Talk and gesture: The embodied completion of sequential actions in spoken interaction. In R. Gardner \& J. Wagner (Eds.), Second language conversations (pp. 221-245). London: Continuum.

[44] Park, I. (2007). Co-construction of word search activities in native and non-native speaker interaction. Working Papers in TESOL \& Applied Linguistics, 7, 1-23.

[45] Rimé, B. (1982). The elimination of visible behavior from social interactions: Effects of verbal, nonverbal and interpersonal variables. European Journal of Social Psychology, 12, 113-129.

[46] Schegloff, E. A. (1984). On some gestures' relation to talk. In J. M. Atkinson \& J. Heritage (Eds.), Structures of social action: Studies in Conversation Analysis (pp. 266-296). Cambridge: Cambridge University Press.

[47] Schegloff, E. A. (2007). Sequence organization in interaction: A primer in Conversation Analysis (v. 1). Cambridge: Cambridge University Press.

[48] Schegloff, E. A., Jefferson, G., \& Sacks, H. (1977). The preference for self-correction in the organization of repair in conversation. Language, 53, 361-382.

[49] Seo, M., \& Koshik, I. (2010). A conversation analytic study of gestures that engender repair in ESL conversation tutoring. Journal of Pragmatics, 42, 2219-2239.

[50] Seyfeddinipur, M. (2007). Repair at hand: Fixing up gestures for recipients. Paper presented at the Annual Conference of American Association for Applied Linguistics, Costa Mesa, CA.

[51] Sidnell, J. (2010). Conversation analysis: An Introduction. Malden, MA: Wiley-Blackwell

[52] Smotrova, T., \& Lantolf, J. P. (2013). The function of gesture in lexically focused L2 instructional conversations. The Modern Language Journal, 97, 397-416.

[53] Stivers, T. (2004). "No no no" and other types of multiple sayings in social interaction. Human Communication Research, 30, 260-293.

[54] Streeck, J. (1993). Gesture as communication I: Its coordination with gaze and speech. Communication Monographs 60, 275299.

[55] Sueyoshi, A., \& Hardison, D. M. (2005). The roles of gestures and facial cues in second language listening comprehension. Language Learning, 55, 661-699.

[56] Swain, M (1985). Communicative competence: Some roles of comprehensible input and comprehensible output in its development. In S. Gass \& C. Madden (Eds.), Input in second language acquisition (pp. 235-253). Rowley, MA: Newbury House.

[57] Taleghani-Nikazm, C. (2008). Gestures in foreign language classrooms: An empirical analysis of their organization and function. In M. Bowles et al. (Eds.), Selected Proceedings of the 2007 Second Language Research Forum (pp. 229-238). Somerville, MA: Cascadilla Proceedings Project

[58] Wang, W., \& Loewen, S. (2015). Nonverbal behavior and corrective feedback in nine ESL university-level classrooms. Language Teaching Research, 20, 459-478.

[59] Willey, B. (2001). Examining a "communication strategy" from a conversation analytic perspective: Eliciting help from native speakers inside and outside of word search sequences. Unpublished master's thesis. University of Illinois at Urbana-Champaign. 
Mi-Suk Seo is Associate Professor in the English Department at California State University, Sacramento, and she teaches courses in grammar, research methods, and second language learning and teaching. Her research interests include conversation analysis, second language acquisition, gesture, intercultural communication, and ESL pedagogy. 